\title{
Attempt at application of the International Classification of Functioning, Disability and Health (ICF) in the domains of body and structure function and activity and participation in the assessment of the rate of disability in patients with morbid obesity - pilot study
}

\author{
KRYSTYN SOSADA ${ }^{1, A}$, MAREK GLUCK ${ }^{2, A}$, ELŻBIETA MIZGAŁA ${ }^{3, D, F}$, WITOLD LUKAS ${ }^{4, A, ~ D-F}$, \\ ALEKSANDRA OLEKSIAK ${ }^{3, A, B, D-F}$, JAKUB PALIGA ${ }^{5, A, B, D, E}$, IRENA BOREK ${ }^{3, B, D}$, \\ WITOLD DRZASTWA ${ }^{3, B, C}$, BERNADETTA IZYDORCZYK ${ }^{6, D, F}$, HANNA MATUSZEWSKA- \\ -ZBROŃSKA ${ }^{3, D, E}$, KAROL ZBROŃSKI7, E, EWA BUJAK-ROSENBEIGER ${ }^{3, E, F}$
}

\author{
${ }^{1}$ Ward of Minimally Invasive, Metabolic, Plastic and Reconstructive Surgery of the Provincial Specialist Hospital, \\ Sosnowiec, Poland \\ ${ }^{2}$ Department and Clinical Ward of General Surgery, Bariatric Surgery and Emergency Medicine of the Medical \\ University of Silesia, Zabrze, Poland \\ ${ }^{3}$ Department of Family Medicine of the Medical University of Silesia, Zabrze, Poland \\ ${ }^{4}$ Faculty of Management, Chair of Public Health of the Czestochowa University of Technology, Czestochowa, Poland \\ ${ }^{5}$ Clinic of Psychiatry and Psychotherapy of the Medical University of Silesia, Katowice, Poland \\ ${ }^{6}$ Department of Clinical and Forensic Psychology of the Silesian University, Katowice, Poland \\ ${ }^{7}$ Medical University of Warsaw, Poland
}

A - Study Design, B - Data Collection, C - Statistical Analysis, D - Data Interpretation, E - Manuscript Preparation, F - Literature Search, G - Funds Collection

Summary Background. Due to the constant increase in the number of morbidly obese patients, an adequate tool for assessing the functioning and disability of these patients is being sought. The International Classification of Functioning, Disability and Health (ICF) could be that tool.

Objectives. The aim of this study is to examine the usefulness of the ICF scale in assessing the functioning of morbidly obese patients in two selected areas in reference to recognized scales.

Material and methods. The study group included 76 patients with morbid obesity qualified for bariatric treatment. The ICF was applied to assess the function and limitations of each individual. Two domains of the ICF were selected: Body Functions and Structures and Activities and Participation. The usefulness of the ICF was compared to that of the Barthel and EPQ-R scales.

Results. In morbidly obese patients, a correlation between motor functions and ICF and BMI, as well as age, was observed. A significant correlation was observed between $\mathrm{BMI}$ and psychomotor control, appropriateness and range of emotions experienced, age and amount of sleep, quality of sleep, memory retrieval and psychomotor functions. Women's mental functions were significantly worse than those of men. In terms of interpersonal relations, a correlation between BMI and regulating behavior within interactions was observed. Conclusions. The ICF is a useful tool for the study and description of the functioning of patients with morbid obesity. The selected domains are described better than by the previously used Barthel scale. Women with morbid obesity tend to have more impaired mental functioning than morbidly obese men.

Key words: ICF, morbid obesity, personality disorders, Barthel scale.

Sosada K, Gluck M, Mizgała E, Lukas W, Oleksiak A, Paliga J, Borek I, Drzastwa W, Izydorczyk B, Matuszewska-Zbrońska H, Zbroński K, Bujak-Rosenbeiger E. Attempt at application of the International Classification of Functioning, Disability and Health (ICF) in the domains of body and structure function and activity and participation in the assessment of the rate of disability in patients with morbid obesity - pilot study. Fam Med Prim Care Rev 2017; 19(2): 156-160, doi: https://doi.org/10.5114/fmpcr.2017.67871.

\section{Background}

According to a prognosis for the year 2030, the number of people suffering from obesity will increase to $33 \%$, a fact that will undoubtedly result in an increase in the number of patients with morbid obesity [1]. The pathological mechanism of obesity, particularly morbid obesity, is very complex, and an increasing number of studies reveal the significant, if not dominant, role of psychological factors associated with its occurrence [1-3]. According to ICD-10 F50.4, obesity is classified among eating disorders as a behavioral disorder, associated with physiological disturbances and physical factors [4].

Data from literature points to a relationship between personality and mood disorders and the prevalence of morbid obesity $[2,5]$. In recent years, a psychological profile of morbidly obese patients has been described: emotional immaturity or immaturity of personality, impaired impulse control with a tendency to deny and avoid problems, as well as low self-esteem [6]. The most common associated psychological issues are depression and anxiety disorders. A frequent cause of obesity is compulsive or non-compulsive overeating $[3,6,7]$. 
The International Classification of Functioning, Disability and Health (ICF) could facilitate the assessment of the functionality of morbidly obese people in relation to their health issues $[8,9]$. The ICF takes into consideration the functioning and structure of the body, activities and participation, as well as environmental and personal factors. Stucki et al. [10] have performed a theoretical comparison of the possible uses of different measures for assessing the functioning of morbidly obese patients.

In order to differentiate the level of disability in patients with morbid obesity qualified to bariatric procedures, we have chosen two domains: Body Functioning and Structure and Activities and Participation.

In order to examine aspects of the functioning of morbidly obese patients, an effort has been made to adjust the scales used in clinical practice - scales which focus on selected personal features (EPQ-R) and scales describing the disability level (Barthel) for the ICF [11-14].

The accepted model for the evaluation of disability can be used to describe any limitations in the daily physical and mental functioning of patients with morbid obesity.

\section{Objectives}

1. To assess the functioning of patients with morbid obesity according to the ICF in two selected domains: Body Functioning and Structure and Activities and Participation, according to gender, age and BMI.

2. To compare the EPQ-R and Barthel scales with the ICF in morbidly obese patients.

\section{Material and methods}

In order to conduct the study, permission from was obtained from the relevant Bioethical Committee (resolution no. KNW/0022/KB1/16/11, 15 February 2011).

The study group consisted of all patients who, from February to December 2011, reported to the bariatric clinic in order to qualify for surgical treatment.

We examined 76 patients with morbid obesity admitted to the general and bariatric surgery department qualified to various surgical procedures. Over $90 \%$ of the patients came to the clinic on their own, after finding the center online or in the press. General practitioners, specialist outpatient clinics, hospitals and clinics referred only $10 \%$. We examined the patients on the second day after their admission to the ward. The study group consisted of patients qualified to bariatric treatments, such as gastric balloon (BIB), adjustable gastric band (AGB), vertical banded gastroplasty (VGB) and Roux-en-Y gastric bypass (RYGB). The remaining inclusion criteria required the age to be above 18 years, BMI above 40 or BMI above 35 plus additional diseases permitting participation in the study, along with the informed consent of the patient. The study ran from February 2011 until December 2013.

Among the 76 patients with morbid obesity, 50 were females and 26 were males. The patients' age varied from 18 to 64 years, with a mean of 41.31 people were single, 45 were in a relationship, 60 were living in urban areas, 16 in rural areas. 13 people had higher education, 32 had high school education, 26 had vocational education and 5 had elementary school education. On the basis of bariatric suggestions, the group was divided into two parts: those below $50 \mathrm{BMI}$ and those above. The first of these groups contained 48 people (63\%); there were 28 (37\%) with BMIs over 50 . The highest BMI was 80.9 . The dividing point of a BMI of 50 was based on the experience of the bariatric surgery department and was a crucial factor in the choice of operating method.

In selecting the appropriate scale for the chosen ICF domains, we relied on the opinions of a panel of experts consisting of psychologists, psychiatrists, bariatric surgeons and general practitioners. This expert group selected two domains:
1) Body Functioning and Structure: in terms of Body Functioning, we have examined motor functions, as well as general mental functions (intellectual, orientation and sleep), and detailed mental functions (cognition, attention, memory and emotional functions);

2) Activities and Participation: we examined self-care (washing oneself and caring for body parts), interpersonal interactions and relationships (family and intimate) and coping in crisis situations.

The scales and questionnaires employed are described below.

The International Classification of Functioning, Disability and Health (ICF) [12] is a multidimensional classification providing an assessment of situations concerning human functioning and disabilities. It is a scale from 0 to 4 describing increasing levels of dysfunction (no impairment, mild, moderate, severe, complete). In this study, we considered physical condition in the following domains: mobility, self-care, interpersonal interactions and relationships and mental functions. Patients were subjected to psychological and psychiatric examination. In total, each patient's function was assessed by 55 items.

As a result of the decision of the expert panel, the following questionnaire-based tools were adopted to assess the previously selected ICF domains:

1) Barthel scale [13], which assesses autonomy in self-care and mobility. The results are interpreted in the following way: $86-100$ points: patient in a non-severe condition; $21-85$ points: patient in a moderately severe condition; $0-20$ points: patient in a severe condition;

2) Eysenck Personality Questionnaire Revised (EPQ-R) [14]. The dimensions of Neuroticism (N) and Extraversion (E) were selected for comparison with the ICF. Neuroticism describes a lack of emotional equilibrium. Extraversion describes the level of openness, impulsivity and reactivity in interpersonal interactions. People scoring average results on the "E" scale receive 0 points (equal to "no impairment") in the ICF. Extreme introversion and extraversion received 4 points ("complete impairment") on the ICF. The highest scores in neuroticism were also graded as 4 .

In order to verify the data obtained in the above-mentioned self-descriptive questionnaire-based tools, and to establish a possible diagnosis of psychological or behavioral disorders, a psychiatrist consulted each patient, and a diagnosis was made according to ICD-10. The same doctor, a member of the research team, examined all patients. Demographic data (gender, age, height, weight and BMI), family histories and eating histories were collected from the patients' documentation.

Patient data on the duration of morbid obesity, along with treatment and associated conditions of developing obesity, will be the subject of a separate publication.

\begin{tabular}{|c|c|c|}
\hline Item & Diagnosis & $n$ \\
\hline 1. & Musculoskeletal disorders & 40 \\
\hline 2. & Hypertension & 25 \\
\hline 3. & Ischemic heart disease & 5 \\
\hline 4. & Diabetes mellitus type 2 & 24 \\
\hline 5. & Gastrointestinal tract diseases & 32 \\
\hline 6. & Asthma & 4 \\
\hline 7. & Omphalocele & 5 \\
\hline 8. & Urinary system diseases & 7 \\
\hline 9. & Thyroid disorders & 3 \\
\hline 10. & Sexual organs disorders & 4 \\
\hline 11. & Sleep apnea & 1 \\
\hline
\end{tabular}




\begin{tabular}{|c|c|c|c|c|c|c|c|c|}
\hline \multirow[b]{2}{*}{ Functions } & \multirow[b]{2}{*}{ d 4101SF } & \multicolumn{7}{|l|}{$p<0.05$} \\
\hline & & d 4102SF & d 4500SF & d 4600SF & d 4601SF & d 4602SF & d 5101SF & d 7202 \\
\hline BMI & 0.252 & 0.317 & 0.358 & 0.449 & 0.396 & 0.423 & 0.332 & 0.272 \\
\hline \multirow[t]{2}{*}{ Age } & 0.227 & 0.159 & 0.293 & 0.260 & 0.384 & 0.330 & 0.196 & 0.055 \\
\hline & \multicolumn{8}{|c|}{$\begin{array}{l}\text { d 4101: squatting } \\
\text { d 4102: kneeling } \\
\text { d 4500: walking short distances } \\
\text { d 4600: moving around within the home } \\
\text { d 4601: moving around within buildings other than home } \\
\text { d 4602: moving around the buildings } \\
\text { d 5101: washing body } \\
\text { d 7202: regulating behaviors within interactions }\end{array}$} \\
\hline
\end{tabular}

\begin{tabular}{|c|c|c|c|c|c|c|c|c|}
\hline \multirow[b]{2}{*}{ Functions } & \multirow[b]{2}{*}{ b 1522SP } & \multicolumn{7}{|l|}{$p<0.05$} \\
\hline & & b 1340SP & b 1341SP & b 1342SP & b 1343SP & b 1442SP & b 1471SP & b 1303 \\
\hline BMI & 0.303 & 0.056 & 0.106 & 0.075 & 0.155 & 0.004 & 0.081 & 0.318 \\
\hline \multirow[t]{2}{*}{ Age } & -0.106 & 0.354 & 0.269 & 0.347 & 0.412 & 0.355 & 0.289 & -0.008 \\
\hline & \multicolumn{8}{|c|}{$\begin{array}{l}\text { b 1522: range of emotion } \\
\text { b 1340: amount of sleep } \\
\text { b 1341: sleep onset } \\
\text { b 1342: sleep maintenance } \\
\text { b 1343: quality of sleep } \\
\text { b 1442: retrieval of memory } \\
\text { b 1471: quality of psychomotor functions } \\
\text { b 1303: overwhelming urge to eat }\end{array}$} \\
\hline
\end{tabular}

Most people were diagnosed with musculoskeletal disorders ( $n=40 ; 52.6 \%) .32$ patients (42.1\%) had gastrointestinal tract diseases. Arterial hypertension was present in 25 patients (32.9\%), whereas diabetes mellitus type 2 was found in 24 patients (31.5\%). 1 patient (1.3\%) had a history of sleep apnea, while psychological disorders were observed in 18 patients (23.7\%).

17 patients $(22.3 \%)$ received three diagnoses, $13(17.1 \%)$ received four diagnoses, and $10(13.1 \%)$ received two diagnoses. Five and six diagnoses were made in 5 patients (6.5\%). Only 4 patients $(5.2 \%)$ had only one co-occurring disease.

The mean age in females was 41 years and ranged from 18 to 64 years. In males, the mean age was 45.5 years, ranging from 33 to 58 years. 3 of the patients with diabetes mellitus type 2 were diagnosed with psychological disorders.

No diagnoses of depressive disorders or depressive episodes (F32, F33) were made in patients with morbid obesity; nonetheless, in 18 patients (23.7\%), other anxiety disorders (F41) were observed. No typical affective disorders were observed, but many patients were characterized as having a "depressive personality", a term that is not present in ICD-10 but is supposed to be implemented in ICD-11 [15]. Patients with such personalities may present themselves as depressed in self-description tools.

The statistical analysis program used was Statistica 12 . The results are presented as absolute numbers and percentages. For comparison of the number of study group, Pearson's chi ${ }^{2}$ test with the Yates correction was used. The correlation coefficient was estimated between ICF items and age and BMI. The level of significance was taken to be $p<0.05$.

\section{Results}

Using the Barthel scale, 52 of the morbidly obese patients (68.4\%) showed slight psychomotor disability, whereas 13 patients' psychomotor state (14.5\%) was assessed as moderately severe. Multiple diseases also occurred in individual patients with morbid obesity (see Table 1 ). The remaining patients were deemed on their own. Assessment of these functions with the ICF revealed significant correlations between age and mobil- ity inside buildings, whereas BMI significantly correlated with kneeling, walking short distances, washing oneself, moving around inside the house and other buildings and outdoor motor activities (Table 2). A significant correlation between age and $\mathrm{BMI}$ and quality of sleep, sleep onset and sleep maintenance, as well as retrieval of memory, was observed (Table 3 ). The results revealed that age (being over 45 years of age) has a significant impact only on regulating behaviors within interactions (Table 2). A significantly more frequent negative assessment of mental functioning was observed in women than men.

In comparison to men, women were significantly more often subject to the inappropriate experiencing of emotions $\left(\mathrm{chi}^{2}\right.$ $=11.62 ; p=0.02$ ), were less stable in terms of controlling emotions $\left(\mathrm{chi}^{2}=8.716 ; p=0.033\right)$, less open to new experiences $\left(\mathrm{chi}^{2}\right.$ $=10.8614 ; p=0.004)$, less optimistic $\left(\mathrm{chi}^{2}=16.36 ; p=0.0026\right)$, less confident $\left(\mathrm{chi}^{2}=18.507 ; p=<0.001\right.$ ) and obtained significantly lower results in terms of parent-child relationships (chi ${ }^{2}$ $=11.69 ; p=0.02$ ). Furthermore, women demonstrated greater difficulties in the retrieval of memory $\left(c^{2} i^{2}=7.3059 ; p=0.025\right)$, thought control (chi $\left.{ }^{2}=15.96 ; p=0.011\right)$, in networking $\left(\mathrm{chi}^{2}=\right.$ 8.92; $p=0.01)$, relationship termination $\left(\mathrm{chi}^{2}=6.398 ; p=0.04\right)$ and in accepting their social role $\left(\mathrm{chi}^{2}=5.04 ; p=0.017\right)$.

\section{Discussion}

The available literature does not describe many evaluation studies using the ICF scale in patients with morbid obesity. Only a few pilot studies have been performed in patients with eating disorders by Tutelyan et al. [9] and Stucki et al. [10].

We have observed a correlation between motor functions and $\mathrm{BMI}$, as well as walking short and long distances, moving around inside the house and other buildings and outdoor motor activities and age.

The ICF assessment of mental state revealed a significant correlation between BMI and psychomotor control, drive, appropriateness of emotions and range of emotions, as well as between age and sleep quantity, sleep onset, sleep maintenance, retrieval of memory and quality of psychomotor functions. 
The aim of the ICF is to enrich clinical assessment, as diagnosis based only on the ICD-10 does not fully reflect the patient's functional state. The ICF also aims to provide a broader perspective on health and illness issues in terms of the human environment and allows for the objective assessment of health and disability states. The ICF is a synthesis of medical and social models and other health conditions and uses a biopsychosocial model of disability $[8,16,17]$. In everyday practice, it is possible to employ only a few domains of the ICF classification, and as a general rule, selecting $20 \%$ of the codes (items) can clarify up to $80 \%$ of the variations observed in the patients studied [8].

Recent studies based on the application of the ICF have revealed that it is a method capable of classifying disability in domains determined by primary disease symptoms [18-20].

In terms of assessing physical capabilities, various authors have indicated that the ICF is far more precise than the widely used Barthel scale. The Barthel scale is easy to use, as it consists of only 10 points, but interpretation of the results leads to far-reaching simplification. For example, 86-100 points indicates that the patient has a slight disability, and completely independent patients belong to this range of scores. A score of 21-85 is defined as a state of moderate severity, and below 20 points means the state is very severe. Thus, the Barthel scale is less precise and may contributes to diagnostic delay. The ICF is faster and more multidirectional in detecting dysfunction; it also takes into account the norm - for example, a 0 on a scale of $0-4$ points was obtained by over $50 \%$ of examined patients on the ICF in terms of overall changes in position, kneeling, bending, moving around indoors, the results showing high or severe dysfunction (more than 3 points). The majority of the study group received the highest possible score, meaning full mobility, which was neither confirmed by the ICF nor clinical assessment.

Analysis of the correlation between groups with BMls of over and below 50 revealed a significant increase in disability in the following domains of motor function: kneeling, walking short and long distances, moving around inside the house and other buildings, outdoor motor activities and washing oneself. The worsening of motor function associated with an increase in body mass is expected and is a result of limitations encountered by patients with morbid obesity. In the domain of motor function, a significant correlation was observed when patients over 45 years of age were considered. In terms of impairment within the Activities and Participation domain, a statistically significant correlation was observed in the parameters of credibility and urge (a sudden overwhelming desire to eat) with BMI.

In terms of quality of sleep, both the age group and the BMI group demonstrated significantly greater impairment. In terms of psychological functioning according to the ICF, we observed that patients with BMIs over 50 have worse functioning in domains of psychomotor control, drive, appropriateness and range of experienced emotions. These results have not been found when other scales where used. Furthermore, we observed that people over 45 years of age function worse in domains associated with amount of sleep, sleep onset, sleep maintenance and quality of sleep, as well as retrieval of memory and quality of psychomotor functions. We observed that women with morbid obesity have worse psychological functioning than men with morbid obesity. In terms of social interactions, a correlation was observed between BMI and behavior control in interpersonal interactions. Women with morbid obesity demonstrated greater impairment in terms of relationships in adult life than did men with the same condition. They were characterized by greater levels of anxiety, uncertainty about oneself and impaired functioning in interpersonal interactions. We have shown a correlation between $\mathrm{BMI}$ and an overwhelming tendency towards urge impulses (such as eating).

Similarly, Tutelyan et al. also found worse mental functioning among women, especially older women, in comparison with men [9].

In the domain of Participation in categories of networking and behavior control in interpersonal interactions, the differences between groups reached statistical significance. In the remaining areas, no statistically significant differences were observed.

Using the ICF also involves limitations associated with the time necessary to complete the questionnaire (over 1 hour) and the need for good knowledge of the patient, and thus sensitivity to hidden problems of the patient (e.g. addictions, violence, etc.) $[10,11]$.

In domains describing psychological function, the ICF is designed differently from most scales aiming to assess psychological state. Most scales are constructed as a continuum between two extremes, with average scores ("normal") in the middle of the scale. In the ICF, an unimpaired or mildly impaired "normal" function is graded 0 to 1 . For this reason, a grade given to a particular impairment does not contain information about its character. The domain of speed of thought may serve as an example: a high score will be obtained in the case of both accelerated and delayed trains of thought. Similarly, in the case of appetite, both increased and decreased appetite will be categorized as impairments. For that reason, the direct comparison of results from psychological tests and scores from the ICF is difficult.

Furthermore, it is necessary to employ the ICF alongside the ICD-10, since various medical entities might seem similar according to the ICF (e.g. appetite disorders in anorexia and bulimia). In connection with the worldwide problem of growing obesity, family physicians can monitor and model healthy behaviors placing special emphasis on tools measuring the extent of patient functioning (e.g. ICF), which may allow for the preparation and implementation of specific preventative programs in patients with obesity [21].

\section{Conclusions}

1. The ICF is a useful tool for studying and describing the physical and mental functioning of patients with morbid obesity. The selected areas are better described than in the case of the previously used Barthel scale. However, we failed to determine whether it is suitable to use the EPQ-R test for the interpretation of results obtained in the ICF in the field of extraversion and neuroticism.

2. Women with morbid obesity tend to have more impaired mental functioning than men with morbid obesity.

Source of funding: The paper was developed under research project No. KNW-2-134/10 "The application of the International Classification of Functioning, Disability and Health (ICF) in the assessment of the rate of disability in patients with morbid obesity".

Conflict of interest: The authors declare no conflict of interests.

\section{References}

1. Finkelstein EA, Khavjou OA, Thompson H, et al. Obesity and severe obesity forecasts through 2030. Am J Prev Med 2012; 42(6): 563-570.

2. Nguyen-Rodriguez S, Unger J, Spruijt-Metz D. Psychological determinants of emotional eating in adolescence. Eat Disord 2009; 17: 211-224.

3. Juruć A, Bogdański P. Osobowość w rozmiarze XXL. Psychologiczne czynniki ryzyka otyłości. Forum Zaburzeń Metabol 2011; 2(1): 34-42 (in Polish). 
4. Klasyfikacja zaburzeń psychicznych i zaburzeń zachowania w ICD-10. Badawcze kryteria diagnostyczne. Kraków, Warszawa: Uniwersyteckie Wydawnictwo Medyczne „Vesalius”, Instytut Psychiatrii i Neurologii; 2000 (in Polish).

5. Szczęsny W, Gniłka W, Dąbrowiecki S, et al. Rola chirurgii w leczeniu otyłości patologicznej. Co lekarz rodzinny wiedzieć powinien? Nowa Med 2009; 16(3): 173-177 (in Polish).

6. Van Hout GCM, Van Oudheusden I, Krasuska AT, et al. Psychological profile of candidates for vertical banded gastroplasty. Obes Surg 2006; 16(1): 67-74.

7. Van Hout GCM, Verschure SKM, Van Heck GL. Psychological predictors of success following bariatric surgery. Obes Surg 2005; 15(4): 552-560.

8. Üstün B, Chatterji S, Kostanjsek N. Comments from WHO for The Journal of Rehabilitation Medicine Special Supplement on ICF Core Sets. J Rehabil Med 2004; 44(Suppl.): 7-8.

9. Tutelyan VA, Chatterji S, Baturin AK, et al. The Health and Functioning ICF-60: development and psychometric properties. Clin Psychol Psychother 2014; 21(1): 437-451.

10. Stucki A, Borchers M, Stucki G, et al. Content comparison of health status measures for obesity based on the international classification of functioning, disability and health. Int J Obes 2006; 30(12): 1791-1799.

11. Cichońska D, Marczak M, Raczkiewicz A, et al. Wykorzystanie Międzynarodowej Klasyfikacji Funkcjonowania, Niepełnosprawności i Zdrowia (ICF) w orzecznictwie lekarskim niepełnosprawności. Zdr Publ 2009; 119(1): 7-13 (in Polish).

12. International Classification of Functioning, Disability and Health. Geneva: World Health Organization; 2001.

13. Mahoney FI, Barthel D. Functionl evaluation: the Barthel Index. MD State Med J 1965; 14; 56-61.

14. Brzozowski P, Drwal Rt. Eysenck Personality Questionnaire EPQ-R: Kwestionariusz Osobowości Eysencka. Polska adaptacja EPQ-R. Warszawa: Pracownia Testów Psychologicznych PTP; 1995; 5-23 (in Polish).

15. Heitzman J, Łoza B, Kosmowski W. Klasyfikacja zaburzeń psychicznych - koncepcyjne założenia ICD-11. Psychiatr Pol 2011; 45(6): 941-950 (in Polish).

16. Stamm TA, Gieza A, Machold K, et al. Applying International Classification of Functioning, disability and health (ICF) in clinical practice. EULAR Congress, Vienna 2005.

17. Gieza A, Evert T. Development of ICF core sets for patients with chronic conditions. J Rehabil Med 2004; 44(Suppl.): 9-11.

18. Ruof J, Cieza A, Wolff B, et al. ICF core sets for diabetes mellitus. J Rehabil Med 2004; 44(Suppl.): 100-106.

19. Geyh S, Kurt T, Brockow T, et al. Identifying the concepts contained in outcome measures of clinical trials on stroke using the International Classification of Functioning, Disability and Health as a reference. J Rehabil Med 2004; 44(Suppl.): 56-62.

20. Brockow T, Duddeck K, Geyh S, et al. Identifying the concepts contained in outcome measures of clinical trials on breast cancer using the International Classification of Functioning, Disability and Health as a reference. J Rehabil Med 2004; 44(Suppl.): 43-48.

21. Kurpas D, Kern JB, Jacquet JP, et al. Programy promocji zdrowia i profilaktyki chorób - przykłady z Europy i USA. Fam Med Prim Care Rev 2015; 17(2): 152-156 (in Polish).

Tables: 3

Figures: 0

References: 21

Received: 04.11.2016

Revised: 21.01.2017

Accepted: 30.01 .2017

Address for correspondence:

Irena Borek, PhD

Katedra i Zakład Medycyny Rodzinnej SUM

ul. 3 Maja 13/15

41-800 Zabrze

Polska

Tel./fax: +48 32 370-43-58

E-mail: iborek@sum.edu.pl 